\title{
miR-203 inhibits ovarian tumor metastasis by targeting BIRC5 and attenuating the TGF $\beta$ pathway
}

Baojin Wang ${ }^{1,2,3^{*}}$, Xia Li $i^{1,2,3}$, Guannan Zhao ${ }^{2,3}$, Huan Yan ${ }^{1,2,3}$, Peixin Dong ${ }^{6}$, Hidemichi Watari ${ }^{6}$, Michelle Sims ${ }^{2,3}$, Wei Li ${ }^{7}$, Lawrence M Pfeffer ${ }^{2,3}$, Yuqi Guo ${ }^{4,5^{*}}$ and Junming Yue ${ }^{2,3^{*}}$

\begin{abstract}
Background: We previously reported that miR-203 functions as a tumor suppressor in ovarian cancer cells by directly targeting transcription factor Snai2 and inhibiting epithelial to mesenchymal transition (EMT), whereas BIRC5/survivin promotes EMT. In this study, we tested our hypothesis that miR-203 inhibits ovarian tumor metastasis by suppressing EMT through targeting BIRC5, using an orthotopic ovarian cancer mouse model.

Methods: We overexpressed miR-203 in ovarian cancer SKOV3 and OVCAR3 cells using a lentiviral vector and examined cell migration and invasion using transwell plates. The small molecule inhibitor, YM155, was used to inhibit survivin expression. miR-203-expressing and control SKOV3 cells were intrabursally injected into immunocompromised NSG female mice. Primary tumors in ovaries and metastatic tumors were collected to determine the expression of survivin and EMT markers using Western blot and immunostaining.

Results: Overexpression of miR-203 inhibits EMT by targeting BIRC5 in ovarian cancer SKOV3 and OVCAR3 cells. miR-203 expression enhances the ability of the survivin inhibitor YM155 to reduce tumor cell migration and invasion in vitro. We further showed that miR-203 expression attenuated the TGF $\beta$ pathway in both SKOV3 and OVCAR3 cells. miR-203 expression also inhibited primary tumor growth in ovaries and metastatic tumors in multiple peritoneal organs including liver and spleen.
\end{abstract}

Conclusion: miR-203 inhibits ovarian tumor metastasis by targeting BIRC5/survivin and attenuating the TGF $\beta$ pathway.

Keywords: miR-203, Ovarian cancer, Survivin, EMT, Tumor metastasis, Orthotopic ovarian cancer mouse model

\section{Background}

Ovarian cancer is one of the most lethal gynecological malignancies, with a five-year survival rate of only $30 \%$ due to intraperitoneal metastasis [1-3]. Most patients have no obvious symptoms and present with advanced to late stage disease that tumors already metastasized into multiple peritoneal organs at diagnosis [4]. The molecular mechanisms underlying the peritoneal metastasis is poorly understood. The epithelial to mesenchymal transition (EMT) is implicated in ovarian tumor metastasis

\footnotetext{
*Correspondence: 307797362@qq.com; yuqi-guo@163.com; jyue@uthsc.edu

'The Third Affiliated Hospital, Zhengzhou University, Zhengzhou, China

${ }^{4}$ Henan Provincial People's Hospital, Zhengzhou, China

${ }^{2}$ Department of Pathology, the University of Tennessee Health Science

Center, 19 S. Manassas St., Rm. 266, Memphis, TN 38163, USA

Full list of author information is available at the end of the article
}

and chemoresistance [5-10]. EMT is a process in which cancer cells lose their epithelial characteristics and acquire mesenchymal properties, thus promoting tumor cell invasion and metastasis. Thus, targeting EMT to inhibit tumor metastasis is an important focus for cancer therapy.

EMT is regulated by transcription factors including Snai1/2, ZEB1/2, and twist1 [11], and by multiple signaling pathways including TGF $\beta$, AKT, ERK1/2, Notch, and WNT [12-15]. miRNAs function by negatively regulating the expression of their target genes at the post-transcriptional level through binding to the 3' untranslated region of target genes. Previous studies showed that miRNAs regulate EMT in different type of cancer cells. miR-448 inhibits EMT by directly targeting E-cadherin repressor Zeb1/2 in breast cancer cells [16].

(C) The Author(s). 2018 Open Access This article is distributed under the terms of the Creative Commons Attribution 4.0 International License (http://creativecommons.org/licenses/by/4.0/), which permits unrestricted use, distribution, and 
miR-302c inhibits EMT by targeting transcription factor AP1 in colorectal cancer [17]. miR-194 inhibits EMT by targeting Bmi1 in glioma [18]. In ovarian cancer, several miRNAs were also shown to regulate EMT by suppressing the expression of multiple target genes. miR-506, miR-382, miR-7, and miR-106 inhibit EMT by directly targeting Snai2, receptor tyrosine kinase orphan receptor 1 (ROR1), EGFR, and ZEB1/2 in ovarian cancer cells, respectively [19-22]. Taken together, these studies indicate that miRNAs are important regulators of EMT in different cancers.

We previously demonstrated that miR-203 is a tumor suppressor miRNA in ovarian cancer and that miR-203 expression inhibits tumor growth by targeting transcription factor Snai2 [23]. We also showed that BIRC5/survivin was highly expressed in ovarian cancer but not in the normal ovary tissues. BIRC5 expression promoted EMT, whereas knockout of BIRC5 inhibits EMT in ovarian cancer cells [24]. BIRC5 was reported to be a target gene of miR-203 in leukemia [25] and hepatocellular carcinoma (HCC) [26], which prompted us to hypothesize that miR-203 may regulate ovarian tumor metastasis by targeting BIRC5 in ovarian cancer cells.

In this study, we demonstrate that miR-203 expression inhibits EMT by targeting BIRC5 in ovarian cancer cells and enhances the efficacy of the survivin small molecule inhibitor YM155 on cell migration and invasion. miR-203 expression also inhibits ovarian tumor metastasis by targeting BIRC5 and attenuating the TGF $\beta$ pathway in an orthotopic ovarian cancer mouse model.

\section{Methods}

\section{Cell culture}

Ovarian cancer cell lines SKOV3 and OVCAR3 were purchased from ATCC and maintained in Dulbecco's Modified Eagle Medium (DMEM) supplemented with 10\% FBS (Hyclone; Logan, UT), $100 \mathrm{U} / \mathrm{mL}$ penicillin, and $100 \mu \mathrm{g} / \mathrm{mL}$ streptomycin (Invitrogen; Carlsbad, CA). miR-203-expressing and control SKOV3 and OVCAR3 stable cell lines were established by transducing both cell lines with lentiviral vector pEF1a-miR-203 vector, and miR-203 expression was detected by polyA tailing RT-PCR as described previously [23]. HEK293 FT cells were purchased from Invitrogen and cultured in DMEM supplemented with 10\% FBS, $100 \mathrm{U} / \mathrm{mL}$ penicillin, $100 \mu \mathrm{g} / \mathrm{mL}$ streptomycin, and $1 \%$ glutamine.

\section{Transwell cell migration assay}

Cell migration assays were performed using modified transwell chambers (BD Falcon ${ }^{\mathrm{TM}}$, San Jose, CA) inserted into 24-well culture plates. miR-203-expressing and control SKOV3 or OVCAR3 cells $\left(3 \times 10^{4}\right)$ were suspended in $300 \mu \mathrm{L}$ serum-free DMEM and added into the upper chamber. DMEM containing 10\% FBS as the chemoattractant was added into the lower chamber of each well and incubated for $24 \mathrm{~h}$. The medium and non-migrated cells in the upper chamber were removed, while the migrated cells on the lower side of the membranes were fixed with methanol and stained with crystal violet. Pictures were taken at $10 \mathrm{X}$ magnification, and cells from at least three different fields were counted.

\section{Wound healing cell migration assay}

Both control and miR-203 expressing SKOV3 and OVCAR3 cells were treated with mitomycin for $4 \mathrm{~h}$ to inhibit cell proliferation and then cultured in serum-free medium for $24 \mathrm{~h}$ with or without YM155. Cell migration index was calculated as described as we published previously [27].

\section{Cell invasion assay}

miR-203-expressing and control SKOV3 and OVCAR3 cells $\left(5 \times 10^{5}\right)$ were seeded in serum-free DMEM onto inserts precoated with Matrigel (BD BioCoat ${ }^{\mathrm{TM}}$ ) using 24-well Tumor Invasion System (BD BioSciences, San Jose, CA). DMEM containing 10\% FBS was added to the bottom chamber as the chemoattractant. The transwell inserts were fixed with methanol for $20 \mathrm{~min}$ and stained for $5 \mathrm{~min}$ with hematoxylin and eosin (H\&E). Pictures were taken at $10 \mathrm{X}$ magnification and invaded cells were counted from at least three different fields.

\section{Immunofluorescent staining}

To detect survivin and EMT markers in human ovarian cancer specimens or cell lines, ovarian tumor sections were antigen-retrieved by heating sections in sodium citrate buffer (10 mM sodium citrate, $0.05 \%$ Tween, $\mathrm{pH}$ 6.0) for 30 mins, while ovarian cancer cells were fixed in $4 \%$ paraformaldehyde for 30 mins. Sections or cells were incubated with blocking buffer (5\% normal goat serum, 3\% bovine serum albumin, and $0.1 \%$ Triton-X100 in PBS) for $1 \mathrm{~h}$, and then incubated overnight with primary antibodies to survivin, PCNA, cytokeratin 7 and vimentin (1:200 dilution, Cell Signaling, Danvers, MA). After rinsing three times for $5 \mathrm{~min}$ with PBST, samples were incubated for $1 \mathrm{~h}$ at room temperature with Alexa 488- or 594-conjugated goat anti-rabbit (Invitrogen, Carlsbad, CA) antibodies. Cell nuclei were counterstained with DAPI (Vector Laboratories, Inc.; Burlingame, CA). Images were captured on a fluorescent microscope (Nikon, San Diego, CA).

\section{Western blot}

Ovarian cancer cells were collected in RIPA buffer (Thermo Scientific; Rockford, IL) containing 1\% Halt Proteinase Inhibitor Cocktail (Thermo Scientific). Equal amounts of protein (40 $\mathrm{\mu g} /$ lane) were loaded onto $10 \%$ SDS-PAGE gels and transferred onto nitrocellulose 
membranes. The membranes were blocked with 5\% nonfat milk for $1 \mathrm{~h}$ and incubated with primary antibodies against survivin (1:1000, Cell signaling); GAPDH (1:5000, Sigma; St. Louis, MO); $\beta$-catenin, vimentin, Snai2 (1:1000, Cell Signaling), and cytokeratin 7 (1:1000, Abcam).

\section{Orthotopic ovarian cancer mouse model}

All animal experiments were performed in accordance with a protocol approved by the Institutional Animal Care and Use Committee at the University of Tennessee Health Science Center. Only immunocompromised NOD.Cg-Prkdcscid Il2rgtm1Wjl/SzJ (NSG) mice (Jackson Laboratory) were used in this study. To generate an orthotopic ovarian cancer mouse model, miR-203-expressing and control stable SKOV3 cells were labelled with luciferase by transduction with the lentiviral vector pEF1a-Luc2. $1 \times 10^{5}$ cells were intrabursally injected into five-week-old females by performing surgery under a dissecting microscopy. Tumor growth and dissemination in NSG mice were subjected to live animal imaging weekly to quantify bioluminescence, immediately after intraperitoneal injection with D-luciferin. Mice were sacrificed at 2-months following cell injection, and tumors were collected for histology, immunofluorescent staining, and Western blot to determine survivin and EMT marker expression.

\section{Statistical analysis}

Significant differences were determined from at least two independent experiments performed in triplicate by Student's $t$-test and data were presented as mean \pm SD. $P<0.05$ was considered significant.

\section{Results}

\section{miR-203 inhibits EMT by targeting survivin in ovarian} cancer cells

In ovarian cancer miR-203 expression is significantly reduced, while BIRC5 is highly expressed, as we published previously [23, 24]. miR-203 is inversely correlated with survivin in ovarian cancer [23]. BIRC5 has been shown to be a miR-203 target in leukemia and hepatocellular carcinoma $[25,26]$. To examine whether BIRC5 is a target gene of miR-203 in ovarian cancer cells, we established miR-203-expressing SKOV3 and OVCAR3 stable cell lines using lentiviral vector as described previously [23]. BIRC5 and EMT marker gene expression was examined in both miR-203-expressing and control SKOV3 and OVCAR3 cells using Western blot. As shown in Figs. $1 \mathrm{a}$ and $\mathrm{b}$, survivin was significantly downregulated in miR-203-expressing SKOV3 and OVCAR3 cells compared to control cells. Mesenchymal markers including Snai2, vimentin, and $\beta$-catenin were also downregulated, while the epithelial marker cytokeratin-7 was upregulated in miR-203-expressing SKOV3 and OVCAR3 cells.
The miR-203 binding site in the 3' UTR of BIRC5 is shown in Fig. 1c. We further validated expression of survivin and EMT markers, including cytokeratin-7 and vimentin, in miR-203-expressing and control SKOV3 cells using immunofluorescent staining. Survivin expression was stained in cell nuclei while vimentin was stained in cell membranes. Both survivin and vimentin expression were downregulated, whereas cytokeratin-7 expression (stained in cell membranes) was upregulated in miR-203-expressing SKOV3 cells compared to controls (Fig. 1d). These results showed that BIRC5 is a target gene of miR-203, and that miR-203 expression inhibits EMT in ovarian cancer cells by targeting BIRC5 in ovarian cancer cells.

miR-203 expression augments the efficacy of the survivin inhibitor YM155 in inhibiting migration and invasion

We previously showed that BIRC5 expression was upregulated in ovarian cancer compared to controls, and inhibition of BIRC5 expression using small molecule inhibitor of survivin YM155 leads to reduced cell migration and invasion [24]. Since BIRC5 is a target gene of miR-203, we hypothesized that miR-203 expression may enhance the efficacy of YM155 to inhibit cell migration and invasion. We first examined the effect of different doses of YM155 on survivin expression, and found that survivin was significantly reduced by YM155 at 40 or $80 \mathrm{nM}$ in both SKOV3 and OVCAR3 cells, as shown by Western blot (Figs. 2a and b). To test whether miR-203 expression affects the efficacy of YM155, we treated miR-203-expressing and control SKOV3 and OVCAR3 cells with 40 nM YM155. miR-203 significantly reduced survivin expression, and addition of YM155 further reduced survivin expression in both cell lines as shown in Figs. 2c and d.

To further test whether miR-203 expression affects the ability of YM155 to inhibit cell migration and invasion, we performed cell migration and invasion assays with or without 40 nM YM155 in miR-203-expressing and control SKOV3 and OVCAR3 cells. miR-203 expression significantly enhanced the ability of YM155 to inhibit cell migration (Fig. 2e) and invasion (Fig. 2f) in both SKOV3 and OVCAR3 cells. In addition, we performed wound healing assay to validate our migration data to exclude the effect of cell proliferation following Mitomycin treatment for $4 \mathrm{~h}$. Consistently, we obtained the similar results in both control and miR-203 expressing SKOV3 and OVCAR3 cells with or without YM155 (Additional file 1: Figure S1A, B) with that from transwell cell migration assay. Our data indicate that miR-203 enhanced the activity of the survivin inhibitor YM155 to inhibit ovarian cell migration and invasion. 


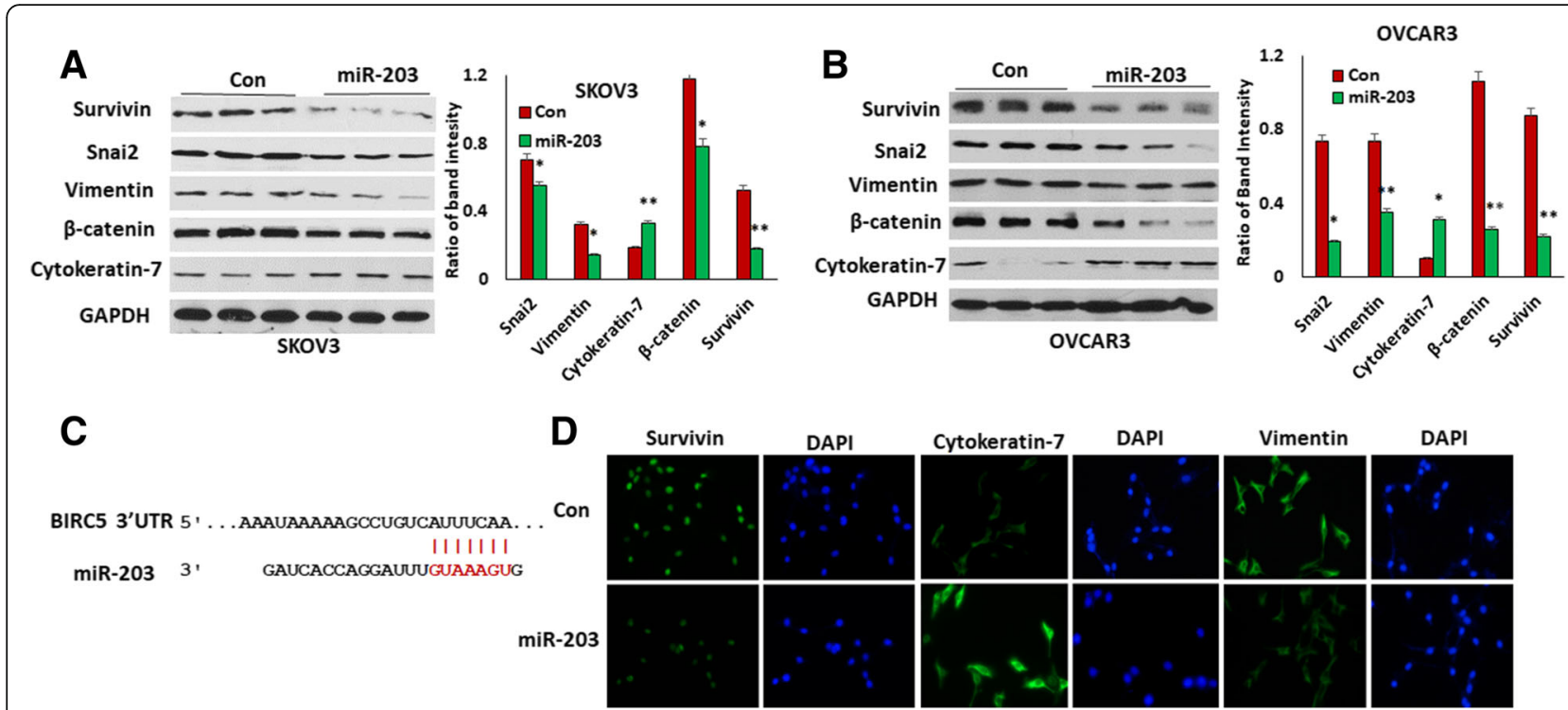

Fig. 1 miR-203 inhibits EMT by targeting BIRC5 in ovarian cancer cells. a, b. Western blot analysis of EMT markers in miR-203-expressing SKOV3 (a) and OVCAR3 cells (b). c, Binding site of miR-203 in BIRC5 mRNA. d. Immunofluorescent staining of survivin and EMT markers in miR-203expressing SKOV3 cells and controls

miR-203 expression attenuates the TGF $\beta$ pathway through targeting BIRC5

We showed previously that TGF $\beta$ promotes BIRC5 expression in ovarian cancer cells, and that knockout of BIRC5 or inhibition of BIRC5 with YM155 attenuated the TGF $\beta$ pathway [24]. Since BIRC5 is a target gene of miR-203, we hypothesized that miR-203 expression may attenuate the TGF $\beta$ pathway by targeting BIRC5. Therefore, we examined the TGF $\beta$ pathway in both miR-203-expressing and control SKOV3 and OVCAR3 cells by detecting phospho-SMAD2 using Western blot. As expected, miR-203 expression significantly attenuated phospho-SMAD2, but did not affect the total SMAD2 in both SKOV3 and OVCAR3 cell lines (Figs. 3a and b). These results suggested that miR-203 expression attenuates the TGF $\beta$ pathway by downregulating survivin, thus inhibiting EMT and tumor metastasis (Fig. 3c).

miR-203 inhibits primary tumor growth and metastasis in an orthotopic ovarian cancer mouse model

Although we showed previously that miR-203 expression inhibits ovarian tumor growth, it is not clear whether miR-203 expression affects ovarian tumor metastasis. Since miR-203 expression inhibits EMT, we hypothesized that miR-203 expression suppresses ovarian tumor metastasis. To test this hypothesis, we intrabursally injected miR-203-expressing and control SKOV3 cells labelled with luciferase into immunocompromised NSG female mice and examined primary tumor growth in ovaries and metastatic tumors in distant organs. Tumor growth in ovaries and dissemination into metastatic organs were monitored using live animal imaging after injecting D-luciferin at one month following cell injection (Fig. 4a). Mice intrabursally xenografted with miR-203-expressing SKOV3 cells showed significantly reduced tumor growth in ovaries (Figs. $4 \mathrm{~b}$ and $\mathrm{c}$ ). Tumors in ovaries were verified in H\&E stained sections (Fig. 4d). Survivin and EMT markers were verified using Western blot from primary tumors and their expression levels were consistent with the data we obtained using cell lines. Survivin, mesenchymal markers, and phospho-SMAD2 were significantly reduced, whereas epithelial marker cytokeratin-7 was upregulated in tumors with miR-203 expression as compared to controls (Fig. 4e). In addition, we also performed immunostaining on primary ovary tumor sections using survivin, vimentin, and cytokeratin-7. Survivin and vimentin were weakly stained, whereas cytokeratin-7 was strongly stained in tumors with miR-203 expression compared to controls (Fig. 4f, g and h). We also examined tumor metastasis in these mice, and tumors were observed in multiple peritoneal organs including liver and spleen in control mice, but tumors were not detected in mice injected with miR-203-expressing SKOV3 cells (Fig. 5a). Invasion of tumors into liver and spleen were observed in H\&E stained sections (Fig. 5b). These results demonstrate that miR-203 expression suppresses primary ovary tumor growth and metastasis by inhibiting EMT through attenuating the TGF $\beta$ pathway.

\section{Discussion}

miRNAs function as tumor suppressors or oncogenes and are associated with tumor metastasis. In this study, 


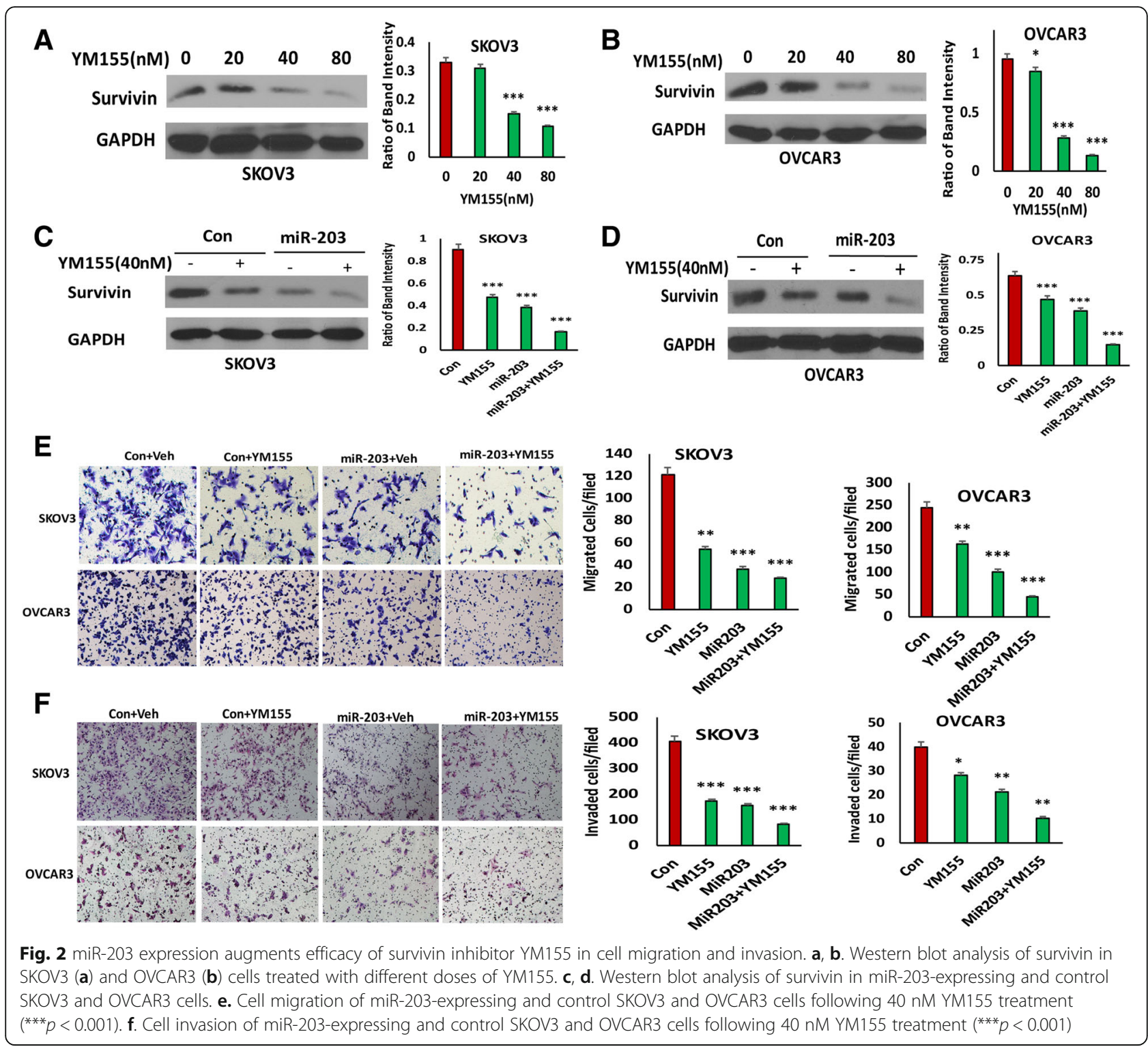

we showed that miR-203 inhibited ovarian primary tumor growth and tumor metastasis by targeting survivin and attenuating the TGF $\beta$ pathway in an orthotopic ovarian cancer mouse model. Our findings validated the role of miR-203 in ovarian cancer by inhibiting primary ovarian tumor growth as a tumor suppressor and provided new experimental evidence that miR-203 inhibits ovarian tumor metastasis by suppressing EMT. miRNAs target multiple genes and downstream pathways. We previously showed that miR-203 inhibits tumor growth by directly targeting transcription factor Snai2 [23]. Here we demonstrated that miR-203-targeted BIRC5, whose expression is significantly upregulated in ovarian cancer compared to normal controls [24]. Therefore, miR-203, as a tumor-suppressing miRNA, inhibits EMT by targeting multiple genes and downstream pathways, thus suppressing tumor metastasis. Therefore, inducing miR-203 expression has therapeutic potential in the treatment of ovarian cancer.

miRNAs either function as tumor suppressors or oncogenes, depending on cellular context. miR-203 has been widely documented as functioning as a tumor-suppressing miRNA by targeting multiple oncogenes in different types of cancers including oral [28, 29], lung [30,31], glioma [32], bladder [33, 34], gastric [35, 36], and colorectal cancers [37], ovarian [23], and breast cancers [38-41]. However, a few studies have found that miR-203 plays an oncogenic role in breast cancer $[42,43]$ or ovarian cancer [44].

Our results show that miR-203 inhibits ovarian cell migration and invasion. As a target gene of miR-203, survivin is highly expressed in multiple cancers including ovarian 


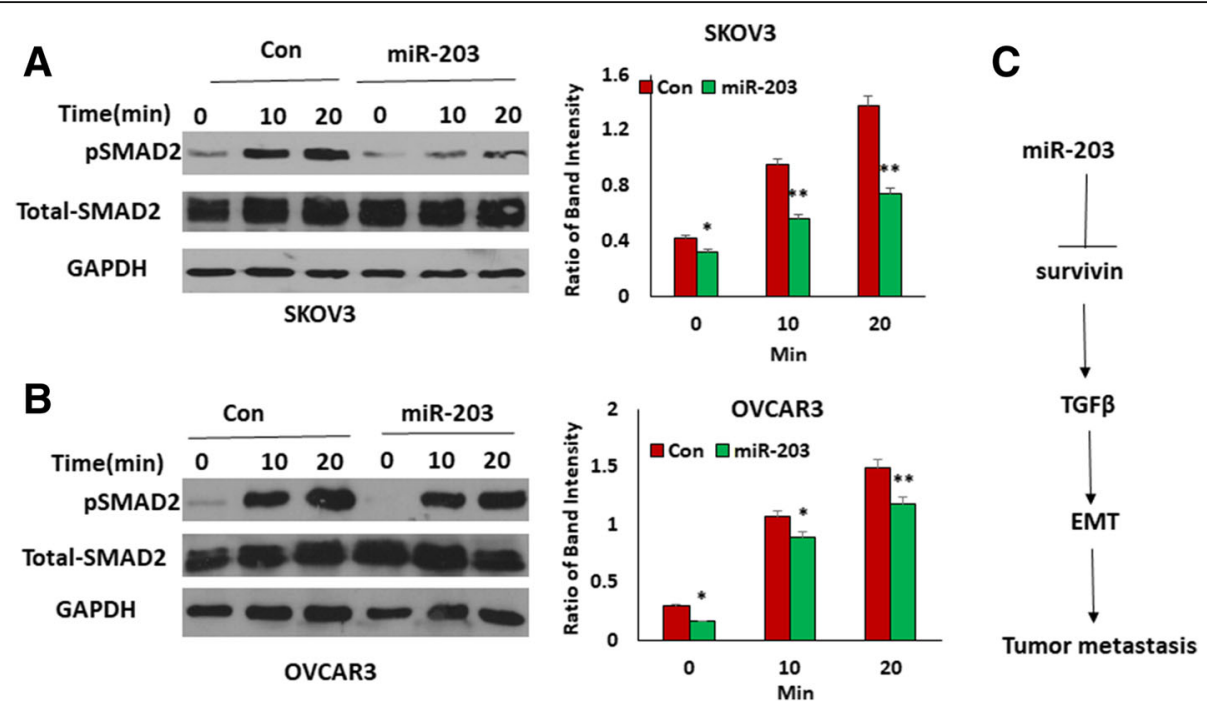

Fig. 3 miR-203 expression attenuates the TGF $\beta$ pathway. a, b. Western blot analysis of phospho- and total SMAD2 in miR-203-expressing and control SKOV3 (a) and OVCAR3 (b) cells. c. A schematic diagram of miR-203 in attenuating the TGF $\beta$ pathway and inhibiting tumor metastasis

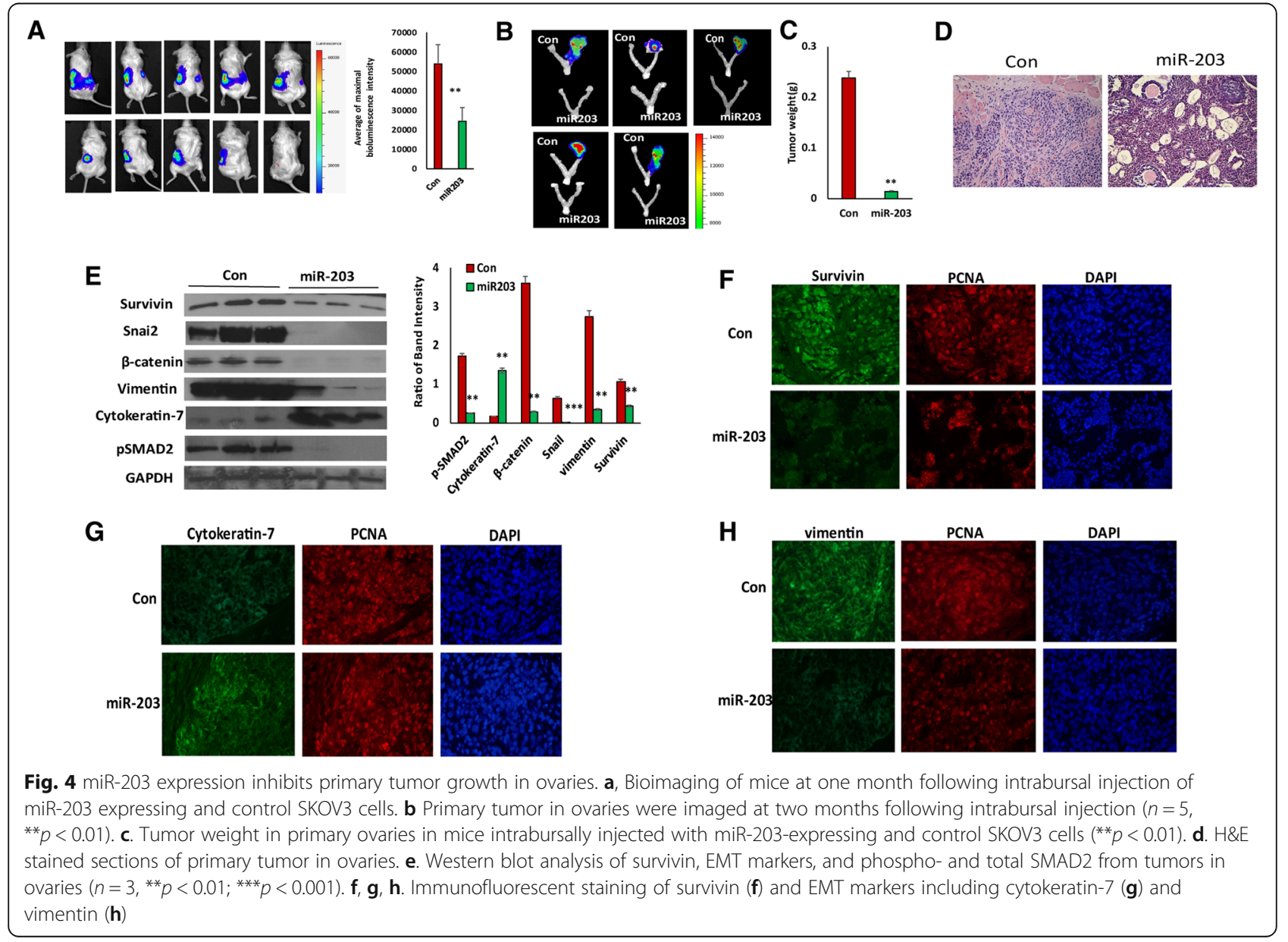




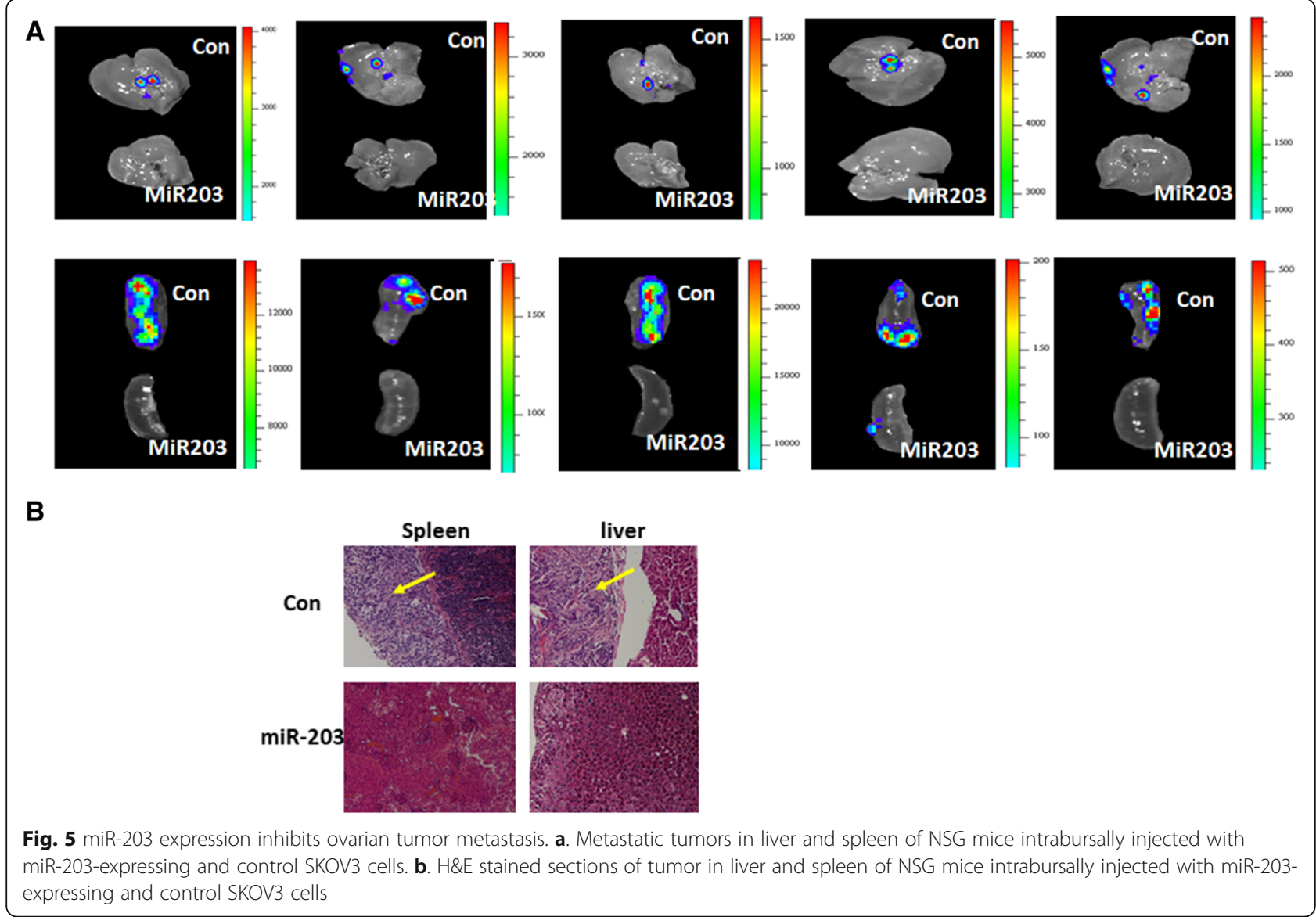

cancer, and the small molecule inhibitor of survivin YM155 has been in clinical trials for several cancer therapies [45-47]. We have previously shown that YM155 inhibited ovarian cell growth, migration and invasion [24]. In this study, we further show that miR-203 expression enhances the efficacy of YM155 in inhibiting BIRC5 expression, and also functionally in suppressing cell migration and invasion (Fig. 2). This result demonstrates that miR-203 can be used as an adjuvant for other chemotherapy drugs, including survivin inhibitors, to improve clinical therapy.

We demonstrated here that miR-203 expression inhibits ovarian tumor metastasis by suppressing EMT through targeting BIRC5, in addition through targeting Snai2, as we reported previously [23]. Recently, we have shown that BIRC5 expression promoted EMT in ovarian cancer cells [24]. Although it is not known how BIRC5 contributes to ovarian tumor metastasis, it is interesting to note that BIRC5 expression was downregulated in ovarian cancer cells by miR-203, suggesting that the miR-203/BIRC5 axis regulates ovarian tumor metastasis by inhibiting EMT.

We showed in this study that mice intrabursally injected with miR-203-expressing SKOV3 cells displayed significantly reduced primary tumor growth and tumor metastasis (Figs. 4 and 5), which validated our hypothesis that miR-203 expression indeed inhibits tumor metastasis by suppressing EMT. We showed previously that TGF $\beta$ promotes EMT in ovarian cancer cells [27]. For the first time, we demonstrated that miR-203 inhibited tumor metastasis by downregulating BIRC5 and attenuating the TGF $\beta$ pathway, BIRC5 is a direct target of miR-203. However, it is not clear how BIRC5 participates in the TGF $\beta$ pathway, which requires further investigation. XIAP (X-linked inhibitor of apoptosis protein), a member of the IAP family, directly interacts with TGF $\beta$ receptor1 (TGF $\beta$ R1) through the BIR domain [48]. It is possible that survivin may activate the TGF $\beta$ pathway through interaction with the BIR domain of survivin in ovarian cancer cells.

\section{Conclusion}

We provided new experimental evidence that miR-203 expression inhibits primary tumor growth in ovaries and peritoneal metastasis in an orthotopic ovarian cancer mouse model by attenuating the TGF $\beta$ pathway, thereby suppressing EMT. 


\section{Additional file}

Additional file 1: miR-203 enhances the efficacy of YM155 in the inhibion of ovarian cancer cell migration. (DOCX $940 \mathrm{~kb}$ )

\section{Abbreviations}

BIRC5: Baculoviral IAP Repeat Containing 5; EMT: epithelial to mesenchymal transition; HCC: hepatocellular carcinoma; NSG: NOD scid gamma

\section{Funding}

This study was supported by a grant from West Cancer Center to J. Yue and partially supported by grants 182300410311(Y, Guo), 18B310031 (B, Wang), 162102410011(Y, Guo) and 16IRTSTHN018(Y, Guo) from Henan Province Educational Board. This study was also supported by $\mathrm{NIH} / \mathrm{NCl}$ grant R01CA193609-01A1 to W. Li and NIH/NCI grant 1R21CA216585-01A1 to J. Yue. Its contents are solely the responsibility of the authors and do not necessarily represent the official views of the $\mathrm{NIH}$.

\section{Availability of data and materials}

Not applicable.

\section{Authors' contributions}

$B W, P D, H W, Y G$, JY designed experiments. BW, XL, GZ, HY, MS performed experiments. $W L, L L, L P, Y G$, JY wrote the manuscript. All authors read and approved the final manuscript.

\section{Ethics approval and consent to participate}

Not applicable.

\section{Consent for publication}

Not applicable.

\section{Competing interests}

The authors declare that they have no competing interests

\section{Publisher's Note}

Springer Nature remains neutral with regard to jurisdictional claims in published maps and institutional affiliations.

\section{Author details}

${ }^{1}$ The Third Affiliated Hospital, Zhengzhou University, Zhengzhou, China. ${ }^{2}$ Department of Pathology, the University of Tennessee Health Science Center, 19 S. Manassas St., Rm. 266, Memphis, TN 38163, USA. ${ }^{3}$ Center for Cancer Research, University of Tennessee Health Science Center, Memphis, TN 38163, USA. ${ }^{4}$ Henan Provincial People's Hospital, Zhengzhou, China. ${ }^{5}$ International Joint Laboratory for Gynecological Oncology Nanomedicine of Henan Province, Zhengzhou, China. ${ }^{6}$ Department of Obstetrics and Gynecology, Hokkaido University School of Medicine, Hokkaido University, Sapporo, Japan. ${ }^{7}$ Department of Pharmaceutical Sciences, the University of Tennessee Health Science Center, Memphis, TN 38163, USA

Received: 8 July 2018 Accepted: 9 September 2018 Published online: 21 September 2018

\section{References}

1. Siegel RL, Miller KD, Jemal A. Cancer statistics, 2017. CA Cancer J Clin. 2017:67(1):7-30

2. Scalici JM, Arapovic S, Saks EJ, Atkins KA, Petroni G, Duska LR, Slack-Davis JK. Mesothelium expression of vascular cell adhesion molecule-1 (VCAM-1) is associated with an unfavorable prognosis in epithelial ovarian cancer (EOC). Cancer. 2017:123(6):977-84

3. Ahmed N, Stenvers KL. Getting to know ovarian cancer ascites: opportunities for targeted therapy-based translational research. Front Oncol. 2013;3:256.

4. Nakayama K, Nakayama N, Katagiri H, Miyazaki K. Mechanisms of ovarian cancer metastasis: biochemical pathways. Int J Mol Sci. 2012;13(9):11705-17.

5. Vergara D, Merlot B, Lucot JP, Collinet P, Vinatier D, Fournier I, Salzet M. Epithelial-mesenchymal transition in ovarian cancer. Cancer Lett. 2010;291(1):59-66
6. Amankwah EK, Lin HY, Tyrer JP, Lawrenson K, Dennis J, Chornokur G, Aben KK, Anton-Culver H, Antonenkova N, Bruinsma F, et al. Epithelialmesenchymal transition (EMT) gene variants and epithelial ovarian Cancer (EOC) risk. Genet Epidemiol. 2015:39(8):689-97.

7. Ahmed N, Abubaker K, Findlay J, Quinn M. Epithelial mesenchymal transition and cancer stem cell-like phenotypes facilitate chemoresistance in recurrent ovarian cancer. Curr Cancer Drug Targets. 2010;10(3):268-78.

8. Helleman J, Smid M, Jansen MP, van der Burg ME, Berns EM. Pathway analysis of gene lists associated with platinum-based chemotherapy resistance in ovarian cancer: the big picture. Gynecol Oncol. 2010;117(2):170-6.

9. Yoshida S, Furukawa N, Haruta S, Tanase Y, Kanayama S, Noguchi T, Sakata M, Yamada $Y$, Oi H, Kobayashi $H$. Expression profiles of genes involved in poor prognosis of epithelial ovarian carcinoma: a review. Int J Gynecol Cancer. 2009;19(6):992-7.

10. Takai M, Terai Y, Kawaguchi H, Ashihara K, Fujiwara S, Tanaka T, Tsunetoh S, Tanaka Y, Sasaki H, Kanemura M, et al. The EMT (epithelial-mesenchymaltransition)-related protein expression indicates the metastatic status and prognosis in patients with ovarian cancer. J Ovarian Res. 2014;7:76.

11. Bogachek MV, Park JM, De Andrade JP, Lorenzen AW, Kulak MV, White JR, Gu WW, Wu VT, Weigel RJ. Inhibiting the SUMO pathway represses the Cancer stem cell population in breast and colorectal carcinomas. Stem Cell Reports. 2016;7(6):1140-51.

12. Bocci F, Jolly MK, Tripathi SC, Aguilar M, Hanash SM, Levine H, Onuchic JN. Numb prevents a complete epithelial-mesenchymal transition by modulating Notch signalling. J R Soc Interface. 2017;14:20170512.

13. Baldwin LA, Hoff JT, Lefringhouse J, Zhang M, Jia C, Liu Z, Erfani S, Jin H, Xu M, She QB, et al. CD151-alpha3beta1 integrin complexes suppress ovarian tumor growth by repressing slug-mediated EMT and canonical Wnt signaling. Oncotarget. 2014;5(23):12203-17.

14. Arend RC, Londono-Joshi Al, Straughn JM Jr, Buchsbaum DJ. The Wnt/betacatenin pathway in ovarian cancer: a review. Gynecol Oncol. 2013;131(3):772-9.

15. Choi JH, Hwang YP, Kim HG, Khanal T, Do MT, Jin SW, Han HJ, Lee HS, Lee $Y C$, Chung YC, et al. Saponins from the roots of Platycodon grandiflorum suppresses TGFbeta1-induced epithelial-mesenchymal transition via repression of PI3K/Akt, ERK1/2 and Smad2/3 pathway in human lung carcinoma A549 cells. Nutr Cancer. 2014:66(1):140-51.

16. Ma P, Ni K, Ke J, Zhang W, Feng Y, Mao Q. miR-448 inhibits the epithelialmesenchymal transition in breast cancer cells by directly targeting the Ecadherin repressor ZEB1/2. Exp Biol Med (Maywood). 2018;243(5):473-80.

17. Ma W, Liu B, Li J, Jiang J, Zhou R, Huang L, Li X, He X, Zhou Q. MicroRNA302C represses epithelial-mesenchymal transition and metastasis by targeting transcription factor AP-4 in colorectal cancer. Biomed Pharmacother. 2018;105:670-6.

18. Zhang X, Wei C, Li J, Liu J, Qu J. MicroRNA-194 represses glioma cell epithelialtomesenchymal transition by targeting Bmi1. Oncol Rep. 2017;37(3):1593-600

19. Sun Y, Hu L, Zheng H, Bagnoli M, Guo Y, Rupaimoole R, Rodriguez-Aguayo C, Lopez-Berestein G, Ji P, Chen K, et al. MiR-506 inhibits multiple targets in the epithelial-to-mesenchymal transition network and is associated with good prognosis in epithelial ovarian cancer. J Pathol. 2015;235(1):25-36.

20. Tan $\mathrm{H}, \mathrm{He}$ Q, Gong G, Wang Y, Li J, Wang J, Zhu D, Wu X. miR-382 inhibits migration and invasion by targeting ROR1 through regulating EMT in ovarian cancer. Int J Oncol. 2016:48(1):181-90.

21. Zhou X, Hu Y, Dai L, Wang Y, Zhou J, Wang W, Di W, Qiu L. MicroRNA-7 inhibits tumor metastasis and reverses epithelial-mesenchymal transition through AKT/ERK1/2 inactivation by targeting EGFR in epithelial ovarian cancer. PLoS One. 2014;9(5):e96718.

22. Guo F, Cogdell D, Hu L, Yang D, Sood AK, Xue F, Zhang W. MiR-101 suppresses the epithelial-to-mesenchymal transition by targeting ZEB1 and ZEB2 in ovarian carcinoma. Oncol Rep. 2014;31(5):2021-8.

23. Zhao G, Guo Y, Chen Z, Wang Y, Yang C, Dudas A, Du Z, Liu W, Zou Y, Szabo $E$, et al. miR-203 functions as a tumor suppressor by inhibiting epithelial to mesenchymal transition in ovarian Cancer. J Cancer Sci Ther. 2015:7(2):34-43.

24. Zhao G, Wang Q, Gu Q, Qiang W, Wei JJ, Dong P, Watari H, Li W, Yue J. Lentiviral CRISPR/Cas9 nickase vector mediated BIRC5 editing inhibits epithelial to mesenchymal transition in ovarian cancer cells. Oncotarget. 2017:8(55):94666-80.

25. Zhang Y, Zhou SY, Yan HZ, Xu DD, Chen HX, Wang XY, Wang X, Liu YT, Zhang L, Wang S, et al. miR-203 inhibits proliferation and self-renewal of leukemia stem cells by targeting survivin and Bmi-1. Sci Rep. 2016;6:19995. 
26. Wei W, Wanjun L, Hui S, Dongyue C, Xinjun Y, Jisheng Z. miR-203 inhibits proliferation of HCC cells by targeting survivin. Cell Biochem Funct. 2013;31(1):82-5.

27. Chen Z, Wang Y, Liu W, Zhao G, Lee S, Balogh A, Zou Y, Guo Y, Zhang Z, Gu W, et al. Doxycycline inducible Kruppel-like factor 4 lentiviral vector mediates mesenchymal to epithelial transition in ovarian cancer cells. PLoS One. 2014;9(8):e105331.

28. Kim JS, Choi DW, Kim CS, Yu SK, Kim HJ, Go DS, Lee SA, Moon SM, Kim SG, Chun HS, et al. MicroRNA-203 induces apoptosis by targeting Bmi-1 in YD-38 Oral Cancer cells. Anticancer Res. 2018;38(6):3477-85.

29. Lim HS, Kim CS, Kim JS, Yu SK, Go DS, Lee SA, Moon SM, Chun HS, Kim SG, Kim DK. Suppression of Oral carcinoma oncogenic activity by microRNA-203 via Down-regulation of SEMA6A. Anticancer Res. 2017;37(10):5425-33.

30. Zhou Y, Liang H, Liao Z, Wang Y, Hu X, Chen X, Xu L, Hu Z. miR-203 enhances let-7 biogenesis by targeting LIN28B to suppress tumor growth in lung cancer. Sci Rep. 2017;7:42680.

31. Chi Y, Jin Q, Liu X, Xu L, He X, Shen Y, Zhou Q, Zhang J, Jin M. miR-203 inhibits cell proliferation, invasion, and migration of non-small-cell lung cancer by downregulating RGS17. Cancer Sci. 2017;108(12):2366-72.

32. Yang CH, Wang Y, Sims M, Cai C, He P, Hacker H, Yue J, Cheng J, Boop FA, Pfeffer LM. MicroRNA203a suppresses glioma tumorigenesis through an ATM-dependent interferon response pathway. Oncotarget. 2017;8(68):112980-91.

33. Shen J, Zhang J, Xiao M, Yang J, Zhang N. MiR-203 suppresses bladder Cancer cell growth and targets the Twist1. Oncol Res. 2017.

34. Zhang X, Zhang Y, Liu X, Fang A, Li P, Li Z, Liu T, Yang Y, Du L, Wang C. MicroRNA-203 is a prognostic Indicator in bladder Cancer and enhances Chemosensitivity to cisplatin via apoptosis by targeting Bcl-w and Survivin. PLoS One. 2015;10(11):e0143441.

35. Gao P, Wang S, Jing F, Zhan J, Wang Y. microRNA-203 suppresses invasion of gastric cancer cells by targeting ERK1/2/slug/ E-cadherin signaling. Cancer Biomark. 2017;19(1):11-20

36. Zhou P, Jiang N, Zhang GX, Sun Q. MiR-203 inhibits tumor invasion and metastasis in gastric cancer by ATM. Acta Biochim Biophys Sin Shanghai. 2016;48(8):696-703.

37. Deng B, Wang B, Fang J, Zhu X, Cao Z, Lin Q, Zhou L, Sun X. MiRNA-203 suppresses cell proliferation, migration and invasion in colorectal cancer via targeting of EIF5A2. Sci Rep. 2016;6:28301.

38. Wang C, Zheng X, Shen C, Shi Y. MicroRNA-203 suppresses cell proliferation and migration by targeting BIRC5 and LASP1 in human triple-negative breast cancer cells. J Exp Clin Cancer Res. 2012;31:58.

39. Lin J, Wang L, Gao J, Zhu S. MiR-203 inhibits estrogen-induced viability, migration and invasion of estrogen receptor alpha-positive breast cancer cells. Exp Ther Med. 2017;14(3):2702-8.

40. Liu J, Yang L, Guo X, Jin G, Wang Q, Lv D, Liu J, Chen Q, Song Q, Li B. Sevoflurane suppresses proliferation by upregulating microRNA-203 in breast cancer cells. Mol Med Rep. 2018.

41. Zhang Z, Zhang B, Li W, Fu L, Fu L, Zhu Z, Dong JT. Epigenetic silencing of miR-203 upregulates SNAI2 and contributes to the invasiveness of malignant breast Cancer cells. Genes Cancer. 2011;2(8):782-91.

42. Ru P, Steele R, Hsueh EC, Ray RB. Anti-miR-203 upregulates SOCS3 expression in breast Cancer cells and enhances cisplatin Chemosensitivity. Genes Cancer. 2011;2(7):720-7.

43. He S, Zhang G, Dong H, Ma M, Sun Q. miR-203 facilitates tumor growth and metastasis by targeting fibroblast growth factor 2 in breast cancer. Onco Targets Ther. 2016;9:6203-10.

44. Xiaohong Z, Lichun F, Na X, Kejian Z, Xiaolan X, Shaosheng W. MiR-203 promotes the growth and migration of ovarian cancer cells by enhancing glycolytic pathway. Tumour Biol. 2016;37(11):14989-97.

45. Clemens MR, Gladkov OA, Gartner E, Vladimirov V, Crown J, Steinberg J, Jie F, Keating A. Phase II, multicenter, open-label, randomized study of YM155 plus docetaxel as first-line treatment in patients with HER2-negative metastatic breast cancer. Breast Cancer Res Treat. 2015;149(1):171-9.

46. Kelly RJ, Thomas A, Rajan A, Chun G, Lopez-Chavez A, Szabo E, Spencer S, Carter CA, Guha U, Khozin S, et al. A phase I/II study of sepantronium bromide (YM155, survivin suppressor) with paclitaxel and carboplatin in patients with advanced non-small-cell lung cancer. Ann Oncol. 2013;24(10):2601-6.

47. Tolcher AW, Quinn DI, Ferrari A, Ahmann F, Giaccone G, Drake T, Keating A, de Bono JS. A phase II study of YM155, a novel small-molecule suppressor of survivin, in castration-resistant taxane-pretreated prostate cancer. Ann Oncol. 2012;23(4):968-73.

48. Neil JR, Tian M, Schiemann WP. X-linked inhibitor of apoptosis protein and its E3 ligase activity promote transforming growth factor-\{beta\}-mediated nuclear factor-\{kappa\}B activation during breast cancer progression. J Biol Chem. 2009;284(32):21209-17.

\section{Ready to submit your research? Choose BMC and benefit from:}

- fast, convenient online submission

- thorough peer review by experienced researchers in your field

- rapid publication on acceptance

- support for research data, including large and complex data types

- gold Open Access which fosters wider collaboration and increased citations

- maximum visibility for your research: over $100 \mathrm{M}$ website views per year

At BMC, research is always in progress.

Learn more biomedcentral.com/submissions 